Bulletin d'Histoire Contemporaine de

I'Espagne

$54 \mid 2020$

Les espaces du politique dans l'Espagne du Trienio liberal (1820-1823)

\title{
Erik ZUBIAGA ARANA, La huella del terror franquista en Bizkaia. Jurisdicción militar, políticas de captación y actitudes sociales (1937-1945)
}

Gaizka FERNÁNDEZ SOLDEVILLA

\section{CpenEdition}

\section{Journals}

\section{Edición electrónica}

URL: http://journals.openedition.org/bhce/3161

DOI: 10.4000/bhce.3161

ISSN: 1968-3723

Editor

Presses Universitaires de Provence

Edición impresa

Fecha de publicación: 1 enero 2020

ISSN: 0987-4135

\section{Referencia electrónica}

Gaizka FERNÁNDEZ SOLDEVILLA, «Erik ZUBIAGA ARANA, La huella del terror franquista en Bizkaia.

Jurisdicción militar, políticas de captación y actitudes sociales (1937-1945) », Bulletin d'Histoire Contemporaine de l'Espagne [En línea], 54 | 2020, Publicado el 01 julio 2020, consultado el 04 enero 2021. URL : http://journals.openedition.org/bhce/3161 ; DOI : https://doi.org/10.4000/bhce.3161

Este documento fue generado automáticamente el 4 enero 2021.

Bulletin d'histoire contemporaine de l'Espagne 


\title{
Erik ZUBIAGA ARANA, La huella del terror franquista en Bizkaia. Jurisdicción militar, políticas de captación y actitudes sociales (1937-1945)
}

\author{
Gaizka FERNÁNDEZ SOLDEVILLA
}

\section{REFERENCIA}

Erik ZUBIAGA ARANA, La huella del terror franquista en Bizkaia. Jurisdicción militar, políticas de captación y actitudes sociales (1937-1945), Bilbao, Universidad del País Vasco / Euskal Herriko Unibertsitatea, 2017, 303 p.

1 La represión franquista desatada durante la Guerra Civil y la inmediata posguerra sigue siendo un tema controvertido, que escapa del ámbito estrictamente académico y suscita lecturas divergentes en partidos políticos, instituciones y sociedad civil. Hoy en día contamos con una amplia bibliografía sobre la maquinaria punitiva de los sublevados. Por desgracia, una parte nada desdeñable de la misma corresponde al género panfletario, escrito por proselitistas sin formación especializada. Estos últimos no solo desprecian la historia como disciplina académica, sino que, además, producen una literatura militante, ad probandum, con nulo respeto por el método y la deontología del historiador. Pese a su escaso rigor, estas visiones tendenciosas cuentan con cierta repercusión mediática y un público fiel: aquel que busca ver confirmadas sus ideas preconcebidas, sus prejuicios.

2 La propaganda franquista inauguró la instrumentalización de las víctimas de la Guerra Civil, empeñándose tanto en minimizar las represalias de los rebeldes como en magnificar las desatadas en la zona controlada por el bando republicano. Algunos 
revisionistas de derechas han seguido este mismo camino, despreciando los resultados que durante las últimas décadas ha cosechado la historiografía profesional. Sin embargo, la manipulación de la historia con fines políticos no es patrimonio exclusivo de una ideología. También abundan las interpretaciones distorsionadas de la contienda en el entorno de la izquierda o de los nacionalismos periféricos.

Una prueba es el notable influjo que, gracias a asociaciones como Euskal Memoria Fundazioa, ha alcanzado la maquinaria publicitaria de la autodenominada "izquierda abertzale". Lo ha hecho no solo en el País Vasco y Navarra, sino incluso en determinados ámbitos del resto de España. El objetivo último de este sector es reinventar la historia de Euskadi para que encaje en los estrechos márgenes de la narrativa de un secular "conflicto" étnico entre vascos y españoles. Desde tal perspectiva, la Guerra Civil no fue más que el penúltimo capítulo de la larga lucha de Euskal Herria por recuperar la perdida independencia originaria. En este sentido, siguiendo la estela de lo que ya hizo la propia ETA en los años sesenta del pasado siglo, el nacionalismo vasco radical ha transmitido una versión deformada de la contienda, que es presentada como la enésima invasión de los españoles (todos ellos fascistas) a la patria de los vascos (todos ellos nacionalistas). Tras su victoria, los primeros se habrían dedicado a perpetrar un "genocidio", intentando borrar a la nación vasca del mapa. Para que el relato no pierda coherencia, los ultranacionalistas "vampirizan" (por utilizar la expresión de Jesús Casquete) a los milicianos de izquierdas y hacen desaparecer a los vascos y navarros franquistas, así como lo sucedido en el resto de España.

4 Sea del signo que sea, el interés de la literatura militante por el pasado siempre es espurio: no busca el avance del conocimiento científico, sino servir a su particular causa política. Tal es la misión del propagandista. Por el contrario, la del historiador es examinar de forma exhaustiva las fuentes disponibles y ofrecer un relato plausible y veraz, elaborado por medio de la metodología propia de su oficio. Si bien la historiografía profesional ha tardado en acercarse a la represión franquista en Euskadi, en los últimos años han aparecido trabajos de índole académica que han comenzado a llenar ese hueco, como los de Pedro Barruso sobre Guipúzcoa y Javier Gómez sobre Álava. ${ }^{1}$ Para completar el mapa del País Vasco hacía falta un estudio serio y concienzudo sobre la tercera provincia y eso es precisamente lo que ofrece La huella del terror franquista en Bizkaia, la versión divulgativa de la tesis de Erik Zubiaga Arana, doctor en Historia Contemporánea por la Universidad del País Vasco e investigador vinculado al Instituto de Historia Social "Valentín de Foronda".

5 La presente obra es fruto de una investigación rigurosa, sólidamente anclada en la consulta de una amplia bibliografía y en fuentes primarias como las custodiadas en el Archivo General Militar de Guadalajara, el Archivo Histórico de Euskadi, el Archivo del Nacionalismo Vasco o el Archivo Intermedio de la Región Militar Noroeste. Apoyándose en tan sólidos pilares, Zubiaga analiza cómo, cuándo y por qué se desarrolló la revancha de los sublevados en Vizcaya durante la Guerra Civil y la inmediata posguerra. El castigo y la amenaza, que buscaban desarticular a las fuerzas leales a la II República y cualquier tipo de disidencia interna, afectó a un elevado número de personas. Aproximadamente 32.100 individuos (tanto vascos como procedentes del resto de España) fueron procesados en la provincia entre 1937 y 1945. A este número hay que sumar los casi 1.500 expedientes contra vascos incoados en Cantabria y Asturias. Es llamativo que un buen número de los procedimientos jurídicos se iniciaran por la denuncia de vecinos o allegados de los acusados: la sociedad vasca, o al menos un sector 
de la misma, fue parte esencial del aparato punitivo de los vencedores, entre los que había numerosos vascos y navarros.

6 Tras soportar unas condiciones de vida extremas en la prisión o en campos de concentración, el $12 \%$ de las causas acabaron con la sentencia a muerte del acusado. El dictador, que tenía tal potestad, conmutó 530 penas capitales por condenas de treinta años de reclusión. No tuvieron tanta suerte los 494 condenados que fueron finalmente fusilados o agarrotados por los franquistas, a pesar de que no pocos de ellos presentaron avales a su favor firmados por sacerdotes o ciudadanos de derechas. Se trata, como el autor no deja de advertir, de una cifra provisional. No obstante, llama la atención que sea superior a la que sostenían autores franquistas como el general Ramón Salas (321) e inferior a la que todavía mantienen propagandistas abertzales como Iñaki Egaña Sevilla (903). Este último no duda en realizar una doble contabilidad, consignar como ejecutadas sentencias que fueron conmutadas, incluir en la nómina a personas fallecidas por causas ajenas a la represión franquista, etc.

7 Hay que destacar que los militantes de partidos y sindicatos de izquierdas fueron los más castigadas por los asesinatos legales. Así, en total 210 izquierdistas fueron ejecutados: 109 socialistas, 39 comunistas, 34 anarquistas y 28 republicanos. 11 víctimas mortales pertenecían a ANV. Siempre en términos relativos, los menos afectados fueron los afiliados al nacionalismo vasco confesional (PNV y STV): 65. Y es que, tal y como había ocurrido en las otras provincias vascas, los ajustes de cuentas del franquismo no afectaron en igual medida a todos los que habían luchado en el bando republicano. No obstante, hay que advertir que el autor no entra en la guerra de cifras, pues se coloca siempre en una perspectiva estrictamente académica.

8 De cualquier manera, la represión franquista no se limitó a las ejecuciones. Existió un relativamente amplio repertorio de medidas punitivas como multas, destierros y procesos de depuración profesional. Además, aunque fuera de forma instrumental, a partir de 1940 la dictadura implementó políticas de captación para atraerse a una parte de los vencidos. Así, el autor indaga en la "redención" de las penas por el trabajo, la revisión de las condenas y otros mecanismos. La "generosidad" del régimen, por llamarla de algún modo, estuvo destinada de manera preferente a los nacionalistas vascos, tanto por considerarles potencialmente integrables como por las gestiones a su favor de la Iglesia Católica y la Italia fascista.

9 El aspecto cuantitativo es, probablemente, el aspecto más llamativo de la tesis de Erik Zubiaga, pero no el único destacable. En realidad, sus grandes aportaciones son la descripción del proceso judicial al que se vieron sometidos los acusados y el apartado interpretativo. Documentalmente el autor confirma que la represión de posguerra en Vizcaya no alcanzó las cotas de virulencia vistas en otros territorios. Entre las posibles causas que explicarían esta singularidad, se enumeran algunas como la institucionalización de la represión, el elevado números de muertes en combate, los pactos de rendición de Bilbao y Santoña, las presiones internacionales, la intercesión de determinados círculos carlistas, la necesidad de mano obra industrial, el reclutamiento forzoso de los milicianos y gudaris capturados en las filas franquistas por las necesidades de una guerra que se preveía de larga duración, el procesamiento de miles de combatientes en Cantabria, la implementación de la política de examen de penas, las políticas de orden del Gobierno Vasco, etc.

10 Erik Zubiaga logra con creces su principal objetivo: explicar el complejo funcionamiento, evolución e impacto de la jurisdicción militar en el área de Vizcaya, 
atendiendo también al vidrioso campo de las actitudes sociales. Lo hace situando el fenómeno dentro de un contexto espacial y temporal muy concreto, como hacen los historiadores. La huella del terror franquista en Bizkaia es un libro de historia honesto, serio y bien documentado. En síntesis, se trata de una obra académica en el mejor sentido de la palabra. Además, impugna frontalmente las manipulaciones históricas llevadas a cabo desde el franquismo y el nacionalismo vasco radical. Es, por tanto, un trabajo necesario, que nos permite manejar datos reales y no elucubraciones interesadas. Solo cabe esperar que la investigación desarrollada en las tres provincias vascas desemboque en una obra de síntesis que nos aporte una visión de conjunto. Hasta entonces, tenemos que felicitarnos por la aparición de La huella del terror franquista en Bizkaia, un ejemplo más de la excelente salud de la joven historiografía vasca.

\section{NOTAS}

1. Pedro Barruso Bares, Violencia política y represión en Guipúzcoa durante la guerra civil y el primer franquismo (1936-1945), San Sebastián, Hiria, 2005, y "La represión en las zonas republicana y franquista del País Vasco durante la Guerra Civil”, Historia Contemporánea, no 35, 2007, p. 653-681. Javier Gómez Calvo, Matar, purgar, sanar. La represión franquista en Álava, Madrid, Tecnos, 2014. Véase también Francisco Espinosa Maestre, "Sobre la represión en el País Vasco", Historia Social, no 63 , 2009, p. 59-75. Puede consultarse una versión revisada y mejorada de este artículo en <http://dialnet.unirioja.es/servlet/articulo?codigo=2914416>

\section{AUTORES}

\section{GAIZKA FERNÁNDEZ SOLDEVILLA}

Historiador. Centro para la Memoria de las Víctimas del Terrorismo 